\title{
The Polarity of War Metaphors in Sports News: A Corpus-Informed Analysis
}

\author{
Tan Kim Hua \\ kimmy@ukm.edu.my \\ Universiti Kebangsaan Malaysia, Malaysia \\ Hamdi Khalis \\ hamdikhalis@gmail.com \\ International Islamic University College of Selangor, Malaysia \\ Nur-Ehsan Mohd-Said ${ }^{a}$ \\ nurehsan@ukm.edu.my \\ Universiti Kebangsaan Malaysia, Malaysia \\ Ong Song Howe \\ guntermgt@gmail.com \\ Ganter Management and Consultancy Sdn. Bhd., Malaysia
}

\begin{abstract}
War metaphors have long been used in sports news reporting. In reality, war metaphors are also used commonly in daily conversations. The wide usage of war metaphors in sports news reporting is because the two domains (i.e. war and sports) are comparable to each other, thereby enabling the use of war terms to describe the sports domain. Following a corpus-informed approach, the strength of modifiers (adjectives) in reversing or retaining the polarity of war metaphors and subsequently affecting news sentiment was examined. Sports news from the BBC Sports News, Malay Mail Online and the Malaysian Online Sports News Corpus, which amounted to 2.3 million words of sports texts, were subjected to corpus analysis. The UCREL Semantic Analysis System identified possible war terms in the corpora and Collocate 2.0 was used to locate adjectives and their respective collocates. Findings indicated that news writers do not necessarily use adjectives as a tool to negate the positive sentiment of news or intensify the negative sentiments. Instead, war metaphors collocated with particular modifiers resulted in a good balance of sports news reported with a negative polarity, positive polarity or a neutral tone.
\end{abstract}

Keywords: war metaphors; news sentiment; adjectives; collocation; sports corpus

\section{INTRODUCTION}

The presence of war metaphors in numerous aspects of our life and speech is a daily occurrence, even though most people have never been involved in an actual war. The role of metaphors in daily conversations is that it acts as an intermediary for different domains in conversations. War metaphors have been used constantly in daily communications for countless occasions and topics. Most people would think that metaphors are only a vehicle to portray poets' imagination and rhetorical language (Lakoff \& Johnson, 1980), while many others think they would be unaffected by the absence of metaphorical expressions in their daily conversations. In reality, the communication process would be significantly complex without the use of metaphors (Mahmoud \& Imran-Ho, 2016). The reason is that certain subjects are better understood when speakers use specific terms from a substantially concrete domain and when

${ }^{a}$ Corresponding author 
cultural references are eminently translatable (Fatemeh et al., 2014). Thus, the use of metaphors is a method of thinking (see Ravichandran, 2011; Sareh et al., 2015) and a tool to shape the thoughts of others.

For decades, war metaphors have been an integral part of the English language. The use of metaphors, including metaphorical expressions based on war experiences, is ubiquitous in our daily conversations. An increasing number of war metaphors, such as besiege, attack, fend off and battle, have been widely used by ordinary people in everyday language (Sun, 2010). The development of new ideas, such as news sports, games, technological devices or products, requires new terms to be created and used. The easiest way to describe new ideas is by infusing terms from existing domains into new domains.

The semantic orientation or polarity of a word indicates the direction that the word deviates from the norm for its semantic group or lexical field (Lehrer, 1974). An adjective can change the way newsreaders view situations. Adjectives have immense influence on the sentiments of readers on the news. For example, although the word 'win' brings a positive connotation in news, the sentiment will falter once the adjective ugly is added before the word win (i.e. ugly win). Accordingly, 'win' may no longer be perceived as positive with a negative indication of the particular situation.

The preceding paragraphs explain two main aspects of this study: war metaphors and adjectives. The main contention of this study is how adjectives can modify the polarity of war metaphors in news writing. The role of adjectives in modifying news sentiment, from positive to negative and vice versa in the context of sports metaphors is examined.

A study on the role of adjectives in orchestrating the portrayal of sports games in the news report is needed to highlight the exploitation of sports news. In determining the fluidity of the nature of adjectives surrounding war metaphors in sports news, this study scrutinised the corpus of the form 'adjective + noun (adjective + war metaphors)' and how this collocational relationship is affected by the adjectives that modify it.

\section{BACKGROUND OF THE STUDY}

\section{WAR METAPHORS}

Metaphorical expressions in discourse can be analysed by 1) descriptive analysis and focusing primarily on the form and frequency of metaphors or 2) focusing on the function, the unveiling of the evaluative and persuasive roles of metaphors.

The form and frequency of metaphors in terms of which parts of speech the metaphors fall were investigated by Steen et al. (2010). They found that metaphorical expressions are mostly verbs with a frequency of 30\% from all the metaphors found. In a study by Sun (2010), on war metaphors in five main areas of everyday English (politics, business, sport, disease, and love), war metaphors were found from all five domains in people's life. However, the meaning of war metaphors differs when used in different domains. For example, the word "battleground" means an election in the political domain, a stock market in the business domain, or the court/field in the sports domain. This study is significant because it helps people understand the contribution of war metaphors in the conceptualisation of these five domains.

A comparative study of war metaphors in the English and Chinese business media discourse conducted by Xian (2017) revealed that the use of war metaphors is extensively shared between English and Chinese business news. He also found that the functions of war metaphors in the business domain are mainly for (1) highlighting financial problems as enemies, (2) establishing a bond with newsreader and (3) producing exaggeration. The findings show that war metaphors are used in news to create a bond with readers and to add an element of suspense. Although differences in lexical terms used have been observed because the lexical 
choice is influenced by the different culture of both languages, the role of war metaphors in business news is discernible.

In commentaries, Chapanga (2004) in his report titled Analysis of the War Metaphors Used in Spoken Commentaries of the Zimbabwe Soccer League proposed that football is comparable to war in terms of the intense competitive spirit between competitors that leads to one team winning over the other. The physical aggression effort among participants is what makes sport comparable to war. Reporters use war metaphors because they intentionally wanted to go overboard in describing the event. The exaggeration of describing an event in a genre can create a feeling of sensation in the audience.

The second approach goes beyond descriptive analysis because this type of analysis looks into the function of metaphors used in discourse. Concerning the evaluative and persuasive roles of metaphors, Comisky et al. (1977) have discussed commentary and its relation to aggressive play in hockey. The results suggested that commentary can influence and alter viewers' perceptions of the action taking place. Though sports news may not be produced live during the match, the commentary and the news provide a play-by-play report. Sports reporting can indeed influence viewer's or reader's perception of the action. The use of war metaphors in sports news can influence the readers/fans to react in a certain way, whether to hate the rival club, to favour a player or to instigate the fans' reaction towards wins and losses.

Sports journalists will usually focus on certain heated matches and rivalries when reporting to sensationalise a sporting event (Bryant et al., 1982; Peterson \& Raney, 2008; Raney \& Kinnally, 2009). Sports commentators and journalists began to increase their duties as storytellers over 40 years ago by maximizing their use of dramatic narration (Bryant et al., 1982; Peterson \& Raney, 2008). For journalists and commentator to produce a dramatic narration of the matches, war metaphors containing negative elements are their targets. The already hostile relationship between fans and athletes from different teams is fuelled by the use of war metaphors in news reporting and result in more attention given by the fans to sports news.

Comisky et al. (1977) conducted a study over 40 years ago on the influence of sports commentary on the emotion of the viewers. Using manipulation tests, the researchers had participants view one of two selected hockey segments with or without commentary and report their level of appreciation and enjoyment of what they viewed. They found that those who watched the clips with the audio commentary perceived their levels of enjoyment to be higher and substantially altered versus those who watched video clips without any audio commentary. Similarly, Bryant et al. (1977) found that intense language, high competition, and strong effort were repeatedly relied upon by sports broadcasters to seemingly enhance the television viewers' level of enjoyment and perceived intensity of the game (Vineyard, 2013). This paper discusses war metaphors from aspects of form, frequency and function.

\section{FLUIDITY OF ADJECTIVES}

Adjectives are a powerful tool in dictating the polarity of news in the written and spoken domain. Descriptive words, such as adjectives or adverbs, play a vital role in 'accompanying' nouns or verbs, which are the core elements of a sentence. A sentence is 'hollow' without descriptive words. In the context of this research, the war metaphors are embedded in the nouns. Adjectives and adverbs are crucial in dictating the polarity of the news according to the writers' directions in addition to making news exciting and newsworthy.

Studies on adjectives in text discourse have consistently been associated with sentiment analysis. These studies have analysed writers' opinions on certain issues through the lexical use of the text. Soomin and Hovy (2006) introduced an approach to exploit the semantic structure of a sentence anchored to an opinion-bearing verb or adjective. Their study presented 
a method to identify the opinion of a holder and topic from online news media texts. The new findings stemming from their study are as follows: (1) analysed verbs and adjectives (not as collocates) to determine the types of sentiment in selected sentences and (2) used a different style of statistical analysis, which involved the analysis of the use of adjectives in online news discourse.

Namrata et al. (2007) studied the sentiments of iconic figures (e.g. politics, sports) in news and blogs. The analysis was based on the modifying words that preceded nouns and found that the portrayals of these figures vary in news and blogs. Some controversial American politicians are portrayed negatively in the news but portrayed positively in blogs. The aforementioned research indicated that this type of study could enable organisations to predict future changes in the market by exploring the general sentiments of the public.

Tan et al. (2017) found that sports news are reported with elements of negativity, such as corruption, drug abuse and bad behaviours, among the sports community because of the pressure to win at all costs. With the evidence of negative elements in sports news, the adjectives used to dictate the sentiments of stories should follow the same trend of negativity. Overall, numerous studies have established the idea of adjectives as determinants of the sentiments of the news (Martin \& White, 2003; Hang, 2015). Although an adjective is not a compulsory element in sentence construction, it brings implied meaning to sentences. Hence, the use of adjectives is pivotal in determining the negativity and positivity of news.

\section{EXPLOITING NEGATIVE BIAS}

Leetaru (2015) conducted sentiment mining on news articles from 1945 to 2005 and found that they were dominated by negative sentiments. Various culturomics studies have also arrived at the same conclusion. Tan et al. (2017) reported that sports news depicts negative sentiments from various themes. News on injuries, corruption, losing teams and drug abuse are often reported by news sites. Negative sentiment is typically inserted in sports news to be considered news-worthy. The Russian news site 'The City Reporter' investigated the effects of news negativity on its news site visitors. For one day, the news site did not report any negative news on any genre of politics or crime. Consequently, the news site lost two-thirds of its average readership. This research indicates that negativity plays a huge role in determining the number of visitors to news sites.

However, this phenomenon is motivated primarily by newsreaders. Soroka (2002) explained that people may choose negative news subconsciously. This outcome has been proven as people on social media (Twitter) tend to retweet tweets containing negative sentiments (Nasir et al. 2011).

Psychologists believe that people opt for negative news because of the negative bias in the human mind. Evidence has shown that people respond immediately to negatively- charged words. In several lab experiments, the response time taken by subjects to hit the response button for the words 'cancer', 'bomb' or 'war' is substantially faster than for the words 'baby', 'smile' or 'fun' (despite these pleasant words being slightly more frequent). Our brain is simply built to be more sensitive towards negative news (Ito et al., 1998). People have the tendency to be able to instantly recognise words with a negative connotation in comparison to positive ones because human beings are by nature more likely to be influenced by negative information. 


\section{MATERIALS AND METHODS}

\section{METHODS}

The principles of corpus linguistics guided the data collection and data analysis process. The corpora comprising multiple sports corpora were compiled for a span of three years. The corpora were analysed using Collocate 2.0 to identify adjectives that collocate with the node words (Ang \& Tan, 2016). A separate qualitative study was conducted to determine the inherent value of adjectives and whether the adjectives that collocate with the war metaphors were positive, negative or neutral in terms of their values (polarity) that were assigned to them. This method can determine the dominant types of adjectives that appear around the node word in the corpus.

The list of positive and negative words produced by Bing et al. (2005) from their research titled 'Opinion Observer: Analyzing and Comparing Opinions on the Web' were used as reference to avoid bias in choosing the polarity of the adjectives. The list of words was derived from data mining across various social media sites. The words were derived from customers' reviews on various products on social media. The social media context of this list is suitable for the current study because news reporting uses the same register and language.

UCREL Semantic Analysis System (USAS) was used to identify possible war terms in the corpora. Given that the site can only process up to 100,000 words at one time, the tagging process had to be done several times. Words with ' $\mathrm{g} 3$ ' tagging represent words related to warfare, defence and the army; weapons were excluded. From the same list, war terms that represent many aspects of sports, such as strategy, players and matches, were identified, matched and excluded. Thereafter, the corpus was further analysed in Collocate 2.0. The adjective + war metaphor collocations were identified based on the list. Usage notes were made on how they were used in the sports news articles. The concordance function helps in locating the war terms occurring in the corpus. Through these processes, the patterns and relationships between adjectives and war metaphorical expression in sports news were produced as illustrated in Fig. 1.

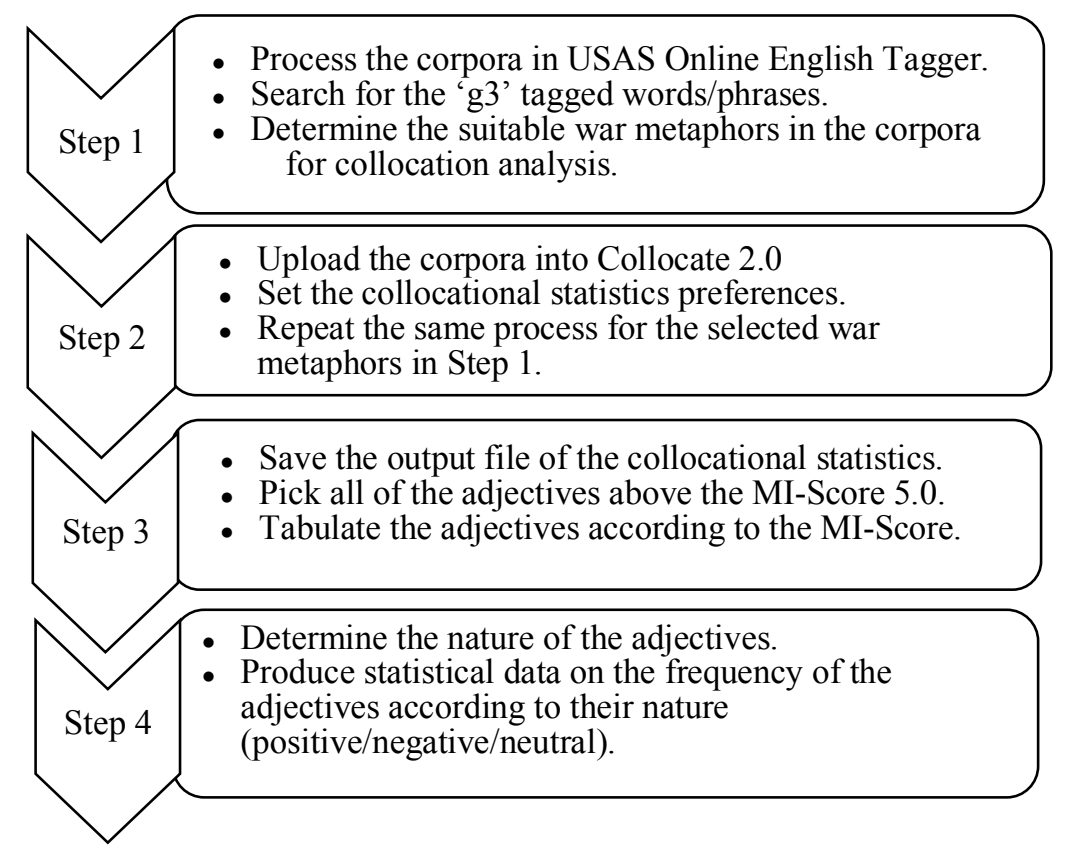

FIGURE 1. Steps for data analysis 
The corpora of the current research were taken from BBC Sports, Malay Mail Online and Malaysian Online Sports News English Corpus (MOSNEC). These corpora, including The Malay Mail Online Corpus, are freely accessible English Corpus. These corpora have a combined total of 2.3 million words. The corpus is limited only to sports and consists of news from selected sports categories (Athletics and Team sports) in the 2005-2006 and 2014-2016 sporting season. No specific number of articles is available from each sport. The length of each article is approximately 300-400 words. (Table 1)

TABLE 1. Corpus used in the current study

\begin{tabular}{ccc}
\hline Corpus & Word Types & Word Tokens \\
\hline BBC Sports & 12,741 & 254,548 \\
Malay Mail Online & 15,091 & 321,729 \\
MOSNEC & 31,718 & $1,731,180$ \\
Total & 59,550 & $2,307,457$ \\
\hline
\end{tabular}

\section{RESULTS}

\section{ANALYSIS OF ADJECTIVES + WAR METAPHORS COLLOCATIONS}

Table 2 shows a list of war-related words produced from the analysis of the corpus using the USAS English Semantic Tagger. The list (Table 2) represents war metaphors identified in the corpus of sports news.

TABLE 2. War Metaphors to be used as node word

\begin{tabular}{cc}
\hline No. & War metaphors \\
\hline 1. & Win \\
2. & Weapon \\
3. & Battle \\
4. & Squad \\
\hline
\end{tabular}

These four words are automatically identified and isolated as war-related thematic terms by the USAS English Semantic Tagger from the corpora used.

The list was obtained by sourcing the Wikipedia page of official war terminologies and confirmed using the USAS English Word Tagger (g3). The war terminologies were assessed and the four war metaphors often used in describing sporting events were identified. These words were analysed based on collocation statistics that signified the strength of association between the adjectives and war metaphors. The larger the MI score, the higher the inclination of association across a span of five words. MI scores above 5 are considered high association. The results are presented in Tables 3, 4, 5 and 6.

TABLE 3. Adjectives + Win collocations (MI score)

\begin{tabular}{ccc}
\hline Positive & $\begin{array}{c}\text { Win } \\
\text { Negative }\end{array}$ & Neutral \\
\hline Resounding & Scratchy Win & Consecutive \\
Win(7.48447) & $(7.06944)$ & Win(8.6544) \\
Comprehensive & Cagey (7.06944) & \\
$(7.06944)$ & Patchy & \\
Precious & $(6.91743)$ & \\
$(6.43201)$ & Crushing & \\
Convincing & $(6.48447)$ & \\
$(6.26738)$ & & \\
\hline
\end{tabular}




\begin{tabular}{cc}
\hline Emphatic & Unimpressive \\
$(6.22813)$ & $(6.33247)$ \\
Priceless & Unconvincing \\
$(5.84704)$ & $(6.19497)$ \\
Historic & Gutsy \\
$(5.48447)$ & $(6.06944)$ \\
& Ugly (5.6544) \\
& Scrappy \\
& $(5.6544)$ \\
& Lopsided \\
& $(5.48447)$ \\
& Eliminating \\
& $(5.48447)$ \\
\hline
\end{tabular}

Table 3 shows the adjective collocations that occurred around the node word 'win'. From the 19 adjectives extracted, 7 of the adjectives had a positive nature whereas 11 had a negative nature and only one adjective was neutral.

The positive nature adjectives were 'resounding', 'comprehensive', 'precious', 'convincing', 'emphatic', 'priceless' and 'historic'. These seven adjectives represented $36 \%$ of the adjectives extracted from the collocation statistical analysis. The adjectives that were negative in nature represented $57 \%$ of all the adjectives that surrounded the node word 'win'. Lastly, a neutral in nature adjective, namely, 'consecutive', represented a mere $5 \%$ of the adjectives that surrounded the node word 'win'.

An interesting insight on adjectives in news reporting was that it relied heavily on the context. A neutral in nature adjective may become negative or positive. If it is a 'consecutive win' then it is positive. However, if it is a consecutive loss then the adjective becomes negative. This kind of adjective relies on the node word to determine its nature.

... secured a resounding 3-0 win and a 3-1 aggregate... (May 2016.txt)

...with a resounding 4-2 win at Palermo, where Gervinho... (MOSNEC_Oct 15 -Mac 16.txt) ...thanks to a resounding 6-2 win over Norwich... (MOSNEC_Oct 15 -Mac 16.txt)

It was expected that a positive event like 'win' in a sports game will be surrounded by a vast number of positive adjectives. The examples above show the adjective 'resounding', which scores a resounding 7.48447 MI score.

Although the node word was 'win', which is a positive word, we can see a large number of negative adjectives also surrounded the node word. Ignoring the context of the news, words like scrappy (5.6544) win, unimpressive (6.33247) win, and ugly (5.6544) win showed something bad that comes out of the good result. Even though the team won, but there was something that was not right.

"So an $\underline{\text { ugly }}$ win can be just as effective as a 30 or 40 point victory. (BBC/123)

The above excerpt shows the manager of the Scotland Rugby Team in the Six Nation Cup stating that they were going to face a tough opponent even though that they are a huge favourite between the two sides. He was trying to justify that it is fine for them to win by a narrow margin as long as they win the match.

...in a blowout win over the visiting Los Angeles Lakers at Oracle Arena. (Mosnec) ...can be happy with such a scrappy win. Dortmund coach Thomas Tuchel, who...

(MOSNEC_Oct 15 -Mac 16.txt)

...It was a scrappy game but a win is a win... (MOSNEC_Oct 15 -Mac 16.txt) 
In this excerpt, the news reported that the Golden State Warriors won with a big margin against their opposition. The word 'blowout' is a negative adjective used to describe a positive event. This example is a perfect one where even though the event was positive, the news report used a negative adjective to describe it.

For the node word 'win', although the word was positive, adjectives with negative nature dominated the collocation statistics produced around the node word. The negative adjectives were mostly used to describe the favourites of the two teams that go against each other in a sports match. Although the favourite team (a team that is expected to win) won the game, the match did not go entirely as expected. Maybe the favourite team did not perform well enough or the underdog managed to give them a good fight.

TABLE 4. adjective + Weapon collocations (MI score)

\begin{tabular}{ccc}
\hline Positive & $\begin{array}{c}\text { Weapon } \\
\text { Negative }\end{array}$ & Neutral \\
\hline Handy weapon & Devastation & Secret weapon \\
$(14.15462)$ & weapon & $(12.07662)$ \\
Ultimate & Attacking & Offensive \\
$(11.8327)$ & $(8.62065)$ & $(11.09573)$ \\
Key (8.01507) & & New $(6.28221)$ \\
Scoring & & \\
$(7.15275)$ & & \\
Major & & \\
$(7.02706)$ & & \\
Best (5.74877) & & \\
\hline
\end{tabular}

The second war metaphor in the findings was the word 'weapon', and the adjectival collocations for the node word weapon are as presented in Table 4. Eleven adjectives were found to collocate with the node word 'weapon'; two were negative adjectives, six were positive adjectives and three adjectives were neutral.

The positive adjectives in the collocation statistics produced were 'handy' (14.15462), 'ultimate' (11.8327), 'key' (8.01507), 'scoring' (7.15275), 'major' (7.02706) and 'best' (5.74877). The positive adjectives 55\% of the adjectives collocated with node word 'weapon'. Although the word 'weapon' was negative, the positive adjectives appeared dominate the collocation statistics of the node word.

...of 13 points at the net, a potentially handy weapon in his arsenal for his next...

$$
\text { (MOSNEC_Dec 14-Sept 15.txt) }
$$

France's ultimate weapon at Euro 2016 is probably not the... (MMO/June 2016.txt)

The drives are a $\underline{\boldsymbol{k e v}}$ weapon for them, big men in the... (MOSNEC_Oct 15 -Mac 16.txt)

The above examples represent several positive adjectives found in the collocation statistics. The adjectives 'handy', 'ultimate', and 'key' indicated the influence that the metaphorical expression represents. The word 'handy' means extremely useful and the player may become the main factor affecting the performance of the player in the next game.

The next word was 'ultimate', which carried the meaning 'simply the best'. In the second example, the news report used 'ultimate weapon' to show the most important factor that will help the France National Football team in the World Cup. The word 'weapon' may refer to a player, coach, fans or anybody involved directly in the team. In this case, 'weapon' 
referred to the France National Team head coach. Thus, the head coach was the most important man in the team according to the news report.

The third example shows the use of the adjective 'key' to describe the war metaphor 'weapon'. Similar to the two previous words, 'key' carried the meaning of something important. In this reporting, the drive (the act of dribbling the basketball directly to the bucket) was a vital play in the team's strategy.

... with her backhand proving a particularly devastating weapon at the Singapore Indoor

Stadium. (MOSNEC_Oct 15 -Mac 16.txt)

...lot of teams using it as an attacking weapon in the 22 this year so there...

(MOSNEC_Oct 15 -Mac 16.txt)

Despite the domination of positive adjectives that collocated with the node word 'weapon', several negative adjectives also appeared in the four left and right window spans of the node word. Based on the above example, the word 'devastation' showed a significance value of (11.73959) while the adjective 'attacking' had (8.62065).

The first example was 'devastating', which based on the context of the news, means the player's backhand is a reliable skill for him/her to acquire points against the opponent. It is generally known that the backhand shot is always weaker in terms of power and skill compared to forehand shot. However, the news reported that this player was very skilful and mastered the backhand shot. The second example showed the use of the adjective 'attacking' to describe the weapon. The news report was talking about the Rolling Maul, which is one of the attacking strategies in rugby where players create a shield-like wall to protect the ball carrier and push the opposition as near to the try zone as they can.

The collocation statistics produced based on the node word 'weapon' showed the domination of positive adjectives compared to negative adjectives, providing that a negative adjective does not need to dominate the collocations with war metaphors in sports news reporting.

TABLE 5. Adjective + Battle collocations (MI score)

\begin{tabular}{ccc}
\hline & Battle & \\
Pogitive & Negative & Neutral \\
\hline enthralling & uphill battle & seesaw battle \\
battle (10.4091) & $(11.73103)$ & $(12.73103)$ \\
pulsating & exhausting & physical \\
$(10.33871)$ & $(10.4091)$ & $(6.97614)$ \\
fascinating & catastrophic & tactical \\
$(9.5611)$ & $(10.14606)$ & $(6.92367)$ \\
thrilling & bruising & decisive \\
$(7.5412)$ & $(9.79243)$ & $(5.89814)$ \\
epic $(7.11632)$ & ferocious & latest $(5.81814)$ \\
interesting & $(9.33871)$ & \\
$(6.66494)$ & vicious & \\
greatest & $(9.14606)$ & \\
$(5.6225)$ & relegation & \\
& $(8.03406)$ & \\
& tight $(8.02137)$ & \\
& fierce $(7.52157)$ & \\
& gruelling & \\
& $(7.37347)$ & \\
& tough $(6.62483)$ & \\
& intense & \\
& $(6.58128)$ &
\end{tabular}


The next war metaphor was 'battle'. Table 5 illustrated that the negative adjectives dominated the collocation statistics with 11 , comprising $46 \%$ of the adjective with significant MI score. Several neutral adjectives were also observed and interestingly, positive adjectives recorded the least number in the statistics. There were six neutral adjectives, making up $25 \%$ of all the adjectives that appeared. The positive adjectives recorded seven occurrences, representing $29 \%$ of all the adjectives that appeared.

\section{The pair traded 16 service breaks during an exhausting baseline battle, with Hrbaty} taking... (BBC/060.txt)

It's always a ferocious battle, no matter who the manager is. (MOSNEC_Oct 15 -Mac 16.txt) Edinburgh contest could end up being a bruising battle of the packs. (BBC/052.txt)

The three examples above represent the negative adjectives that surround the node word 'battle' in the corpus analysed. The first example shows the adjective 'exhausting' battle, which meant the tennis players in the news report underwent long and tiresome baseline rallies in the match. Baseline play in tennis is known for its extremely demanding conditions in which players have to run all over the base of the court to get the ball.

The second example shows the word 'ferocious' used to describe the node word 'battle'. Bringing in the context of the news report in the explanation, the news was on the match between two great rivals in English Premier League, the Manchester United and Liverpool. The two teams had undergone managerial changes in the past few years. However, the rivalry is still one of the most looked forward to by the fans and a win over the rival is sought after by the players, fans and the managers of the teams. The next example shows the word bruising. The news was on the Italian rugby team captain talking about their match against the Scotland Rugby team, hence the reference to the Edinburgh contest. Because rugby is a contact sport, the adjective 'bruising' is suitable to be used in the report. The Italian said that both teams are looking for their first win of the Rugby Six tournament and will do whatever it takes to top the other.

...was pleased to have got through her seesaw battle with the Romanian and while she...

(MOSNEC_Dec 14-Sept 15.txt)

...needed four set points to carry the tight battle into a deciding set. But that...

(MOSNEC_Dec 14-Sept 15.txt)

The two examples above are some of the neutral adjectives found in the collocation statistics produced by the node word 'battle'. The first example is 'seesaw', which carries the meaning of a match that saw both players/teams took the lead over the other multiple times. The second example shows the word 'tight' used to describe a battle. It means the match is a competitive one. On its own, tight is a neutral adjective. However, it changes when put into the context such as in this news report. From the audience point of view, it was an exciting match with lots of action but became negative because it may be an exhausting game for both players/teams.

...Andrey Kuznetsov over three sets in an enthralling battle. Nadal won 6-3, 5-7, 6-4 but...

(MOSNEC_Oct 15 -Mac 16.txt)

Most Valuable Player Curry scored 35 points in a pulsating battle in Oakland...

(MOSNEC_Oct 15 -Mac 16.txt)

Lastly, the positive adjectives that appeared around the node word 'battle' generally show how exciting the match was. Both examples above carry a similar meaning, to show that 
the match between the two oppositions was close and action-packed. The first news excerpt reported that the match is enthralling because it had to go to the third set. The second excerpt reported about a basketball match between Golden State Warriors and Houston Rockets wherein the Houston Rockets came close to a comeback. However, after the action-packed four quarters of the game, the Golden State Warriors emerged as the winner.

TABLE 6. adjectives + squad collocations (MI score)

\begin{tabular}{ccc}
\hline Positive & $\begin{array}{c}\text { Squad } \\
\text { Negative }\end{array}$ & Neutral \\
\hline tireless squad & unbalanced & youngest squad \\
$(8.91395)$ & squad (9.32898) & $(6.39039)$ \\
revamped & underperforming & senior (6.30251) \\
$(7.91395)$ & $(8.91315)$ & provisional \\
boasting & demoralised & $(6.00706)$ \\
$(7.21351)$ & $(8.91315)$ & balanced \\
talented & depleted & $(5.74402)$ \\
$(5.43821)$ & $(7.66602)$ & \\
& ravaged & \\
& $(7.21351)$ & \\
& weakened & \\
& $(6.82648)$ & \\
& unavailable & \\
& $(6.52163)$ & \\
& inexperienced & $(5.91395)$ \\
\end{tabular}

The fourth war metaphorical expression used as the node word in the analysis was the word 'squad' and the adjectival collocations are listed in Table 6. Similar to the node word 'battle', the adjectives that collocated with 'squad' were dominated by negative adjectives. There were eight significant negative adjectives (50\% of all the significant adjectives). The positive and neutral adjectives were four occurrences each, representing only $25 \%$ of all the adjectives found in the collocation list.

...against Turkey, as he bids to revive a demoralised squad to host the World Cup in... (MMO/August 2016.txt)

...one senior centre-back available from his injury-ravaged squad to face Premier League leaders... (MOSNEC_Oct 15-Mac 16.txt)

The examples above are some of the examples that contain negative adjectives. The first example shows that the negative adjective 'demoralised' collocates with the node word 'squad'. It was reported that the Russia Football team manager dropped a few players that failed to reach their expectations from the last tournament. The use of the adjective 'demoralised' shows that the problem with the team was not in terms of skills but their mental and emotional condition. The second example shows the negative adjective 'ravaged' that collocated with the node word 'squad'. The word 'ravaged' means badly damaged and with this report, it meant that the team was in bad condition as too many important players were injured.

Souness wants to add the £3m-rated Portugal international to his revamped squad during the transfer window. (BBC/195.txt)

...focus is now on ensuring our talented squad reaches its potential... (MOSNEC_Oct 15 Mac 16.txt) 
Both examples show the positive adjectives collocate with the node word squad. The first example contains the phrase "revamped squad" which means improved squad. Based on the context, the team manager added a few new players during the transfer window and in addition to that, the manager wanted to add a Portuguese player into the already improved squad. The second example contains the phrase "talented squad", which means the squad is full of talents. Based on the news context, the manager of the team is keen to use young players as they are talented and wanted to make sure that this young team received a lot of game time to be better players in the future.

\section{DISCUSSION}

The analysis illustrated the role of adjectives in modifying war metaphors in news reporting. The types of adjectives used changed the polarity of the sports metaphors from negative to positive or vice versa. In some instances, they remained neutral.

The analysis indicates that negative modifiers dominate a significant number of collocations produced from the different aspects of sports news. In several aspects, such as results portrayal, game players and matches or the team, negative modifiers appear to be significantly collocated with the node words.

The domination of negative modifiers to alter the sentiment of the news shows that news writers take advantage of the negative bias. A few phrases, such as 'patchy win', 'unconvincing win' and 'scrappy win', indicate that the win alone was insufficient for the team to be portrayed in a positive light. Different angles, such as the last match performance, momentum of the team early in the season and losing/winning streak, will be considered part of the news information that provides opportunities for writers to include negative elements in the report.

This is similar to the other three-node words, namely, 'weapon', 'battle' and 'squad'. Negative modifiers dominate the statistics produced based on the Mutual Information Scores (MI-score). Such modifiers as 'exhausting', 'catastrophic' and 'bruising' indicate that the battle (referring to sports matches) is modified into portraying a negative sentiment. The writers examined the matches from several points of view, such as from its score line, injuries during matches, fouls committed and players' performance. One interesting finding from this study is the use of the metaphor 'relegation battle'. Although it initially brings a natural indication, the modifier 'relegation' became negative after examining the context of the news. 'Relegation' in sports matches means the team is demoted into lower-tier leagues, thereby affecting the team negatively in terms of revenues, fans, stadium attendance and clubs' prestige level. For a team to avoid relegation, they have to win matches, play hard and deliver gritty matches to overcome the odds. These matches are described as 'exhausting battle' or 'bruising battle'.

The effects from these exhausting or bruising matches were often depicted on the squad involved in those battles. News writers use such modifiers as 'demoralised' and 'depleted' to describe the teams that lost in intense matches. News writers also tend to use modifiers, such as 'inexperienced', to describe rookie teams that have no experience playing in a new football league. This situation shows the tendency of news writers to view the news from a negative perspective. Numerous positive perspectives can be discussed about these teams. Despite the lack of experience, these teams consistently show considerable passion and are often energetic and athletic. However, news writers chose to employ the term 'inexperienced team' instead.

The collocational analysis shows more negative adjectives than positive adjectives. However, the difference was not wide, because a $4 \%$ difference between the occurrences of negative (42\%) and positive (38\%) adjectives was observed. The neutral in nature adjectives recorded the least number among all types of adjectives with only 19 occurrences ( $20 \%)$. 
War is always associated with negativity because it causes deaths and sufferings. However, when war terms are metaphorically used in the sports domain, it is not necessarily so. Overall, there is a good balance of positive and negative adjectives preceding the war metaphors in the corpus.

\section{CONCLUSION}

In summary, this study analysed the collocation statistics of adjective + war metaphors and demonstrated the role of adjectives in modifying the sentiments of war metaphors in sports news reporting. For all intents and purposes, news writers knowingly pair war metaphors in sports news with specific adjectives.

The findings of this research demonstrated the role of adjectives as sentiment modifiers in online sports news. That is, good news can be turned into bad news by using particular adjectives and vice versa. Collocating a positive adjective to a sports metaphor inbad news can influence news perception rendering it good news. The use of adjectives is thus crucial and also necessary in news reporting. Without these modifiers, there will be an absence of the element of exaggeration and pulling effect of news report, which would make news reports rather stale and uninteresting. News writers are either able to exploit the notion of negativity biasness inherent in a majority of news or highlight positivity with the use of positive modifiers in news reporting. Adjectives can be manipulated to influence or change the polarity of war metaphors. The role of adjectives in influencing the sentiment of news reports must not therefore be overlooked nor undermined, particularly in sports news.

\section{ACKNOWLEDGMENT}

Part of this research is supported by research grant coded GGPM-2019-012, Universiti Kebangsaan Malaysia.

\section{REFERENCES}

Ang, L. H., \& Tan, K. H. (2016). Preposition-Related Collocation use among British and Malaysian Learners: A Corpus Analysis. Pertanika Journal of Social Sciences \& Humanities, 24, 145-156.

Bing, L., Minqing, H., \& Junsheng, C. (2005). Opinion Observer: Analyzing and Comparing Opinions on the Web. Proceedings of the 14th International World Wide Web conference. https://doi.org/10.1145/1060745.1060797

Bryant, J., Comisky, P., \& Zillmann, D. (1977). Drama in Sports Commentary, Journal of Communication. 27(3), 140-149.

Bryant, J., Brown, D., Comisky, P. W., \& Zillman, D. (1982). Sports and Spectators. Commentary and Appreciation, Journal of Communication. 32(1), 109-119.

Chapanga, E. (2004). An analysis of the war metaphors used in spoken commentaries of the 2004 edition of the Premier Soccer League (PSL) matches in Zimbabwe. Zambezia. $31(1 / 2), 62-71$.

Comisky, P., Bryant, J. \& Zillmann, D. (1977). Commentary as a Substitute for Action, Journal of Communication. 27(3), 150-153.

Fatemeh, S., Imran-Ho, A. \& Norsimah, M. A. (2014). Cultural Basis of Metaphors Translation: Case of Emotions in Persian and English. Asian Social Science. 10(7), 107118. 
Hang, S. (2015). Judgement and adjective complementation patterns in biographical discourse: A corpus study. Unpublished doctoral dissertation, University of Birmingham, Birmingham, United Kingdom.

Ito, T. A., Larsen, J.T., Smith, N.K., \& Cacioppo, J. T. (1998) Negative information weighs more heavily on the brain: the negativity bias in evaluative categorizations. J Pers Soc Psychol. 75(4), 887-900. doi: 10.1037//0022-3514.75.4.887

Lakoff, G., \& Johnson, M. (1980). Conceptual metaphor in everyday language. The Journal of Philosophy. 77(8), 453-486.

Leetaru, K. H. (2015). Mining libraries: Lessons learned from 20 years of massive computing on the world's information. Information Services \& Use. 35, 31-50.

Lehrer, A. (1974). Semantic fields and lexical structure. American Elsevier.

Mahmoud, A. \& Imran-Ho, A. (2016). The Impact of Output Communication on EFL Learners' Metaphor Second Language Acquisition. The Social Sciences. 11(9), 19401947.

Martin, J. R., \& White, P. R. (2003). The Language of Evaluation. Palgrave Macmillan.

Namrata, G., Manjunath, S., \& Skiena, S. (2007). Large-Scale sentiment analysis for news and blogs. International Conference on Weblogs and Social Media, 7(21), 219-222.

Nasir, N., Gottron, T., Kunegis, J., \& Arifah, C. A. (2011). Bad news travel fast: A contentbased analysis of interestingness on twitter. Proceedings of the 3rd international web science conference, ACM WebSci '11.

Peterson, E. M., \& Raney, A. A. (2008) Reconceptualizing and reexamining suspense as a predictor of mediated sports enjoyment, Journal of Broadcasting \& Electronic Media. $52(4), 544-562$.

Raney, A. A. \& Kinnally, W. (2009). Examining Perceived Violence and Enjoyment of Televised Rivalry Sports Contests. Mass Communication \& Society. 12(3), 311-331

Ravichandran, V. (2011). Metaphors as Ideological Constructs for Identity in Malaysian Short Stories. 3L: The Southeast Asian Journal of English Language Studies. 17 (Special Issue), 99-107.

Sareh, J., Imran-Ho, A. \& Ravichandran, V. (2015). A Traveler in God's Path: Sufi Words and the Metaphor of Journey. Asian Social Science. 11(16), 160-167.

Steen, G. J., Dorst, A. J., Herrmann, B. J., Kaal, A., Krennmayr, T., \& Pasma, T. (2010). A Method for Linguistic Metaphor Identification: From MIP to MIPVU. Converging evidence in Language and Communication Research, 14. Amsterdam and Philadelphia: John Benjamins.

Soomin, K., \& Hovy, E. H. (2006). Extracting opinions, opinion holders, and topics expressed in online news media text. SST '06: Proceedings of the Workshop on Sentiment and Subjectivity in Text.

Soroka, S. N. (2002). Issue Attributes and Agenda-Setting by Media, the Public, and Policymakers in Canada. International Journal of Public Opinion Research. 14(3), 264-285.

Sun, L. (2010). A cognitive study of war metaphors in five main areas of everyday English: Politics, Business, Sport, Disease and Love. Sweden: Högskolan Kristianstad, Sektionen för Lärarutbildning

Tan, K. H., Mohammad, Abdollahi-Guilani, \& Fatin Nazihah Ahamad Rusly. (2017). Negativity as Criteria for Newsworthiness in Malaysian Newspaper Sports Corpus. Malaysian Journal of Communication, 33(2), 105-119.

Xian, Z. (2017). A comparative study of war metaphors in English and Chinese business media discourse. Master dissertation, Lingnan University. Retrieved from http://commons.ln.edu.hk/eng_etd/13/ 


\section{ABOUT THE AUTHORS}

Tan, Kim Hua (Ph.D), is an Associate Professor at the Faculty of Education, Universiti Kebangsaan Malaysia. Her research interests are in corpus-based research, corpus lexicography and the social impact of higher education in society. She currently leads the journal of Higher Education and Oriental Studies.

Hamdi Khalis is a lecturer at International Islamic University College of Selangor. He was conferred the Masters in English Language Studies at Universiti Kebangsaan Malaysia.

Nur-Ehsan Mohd-Said is senior lecturer at the Faculty of Education, Universiti Kebangsaan Malaysia. He obtained his Ph.D. in English Language and Linguistics from the University of Sheffield, United Kingdom. His research interests include language attitude, differentiated instruction, and classroom research in an ESL setting.

Ong Song Howe is the Executive Director of Ganter Management and Consultancy Sdn. Bhd. 